\title{
Effect of Wetting on the Ability of Nanomaterials to Act as Effective Catalysts
}

\author{
Michael W. Cross ${ }^{1 *}$, Walter J. Varhue ${ }^{2}$, M. Ryan McDevitt ${ }^{2}$, Darren L. Hitt ${ }^{2}$ \\ ${ }^{1}$ David Crawford School of Engineering, Norwich University, Northfield, VT, USA \\ ${ }^{2}$ School of Engineering, University of Vermont, Burlington, VT, USA \\ Email: ^mcross2@norwich.edu
}

How to cite this paper: Cross, M.W., Varhue, W.J., McDevitt, M.R. and Hitt, D.L. (2016) Effect of Wetting on the Ability of Nanomaterials to Act as Effective Catalysts. Advances in Chemical Engineering and Science, 6, 541-552.

http://dx.doi.org/10.4236/aces.2016.65047

Received: October 18, 2016

Accepted: November 20, 2016

Published: November 23, 2016

Copyright $\odot 2016$ by authors and Scientific Research Publishing Inc. This work is licensed under the Creative Commons Attribution International License (CC BY 4.0).

http://creativecommons.org/licenses/by/4.0/ (c) (i) Open Access

\begin{abstract}
The ability of some nanostructured materials to perform as effective heterogeneous catalysts is potentially hindered by the failure of the liquid reactant to effectively wet the solid catalyst surface. In this work, two different chemical reactions, each involving a change of phase from liquid to gas on a solid catalyst surface, are investigated. The first reaction is the catalyzed decomposition of a $\mathrm{H}_{2} \mathrm{O}_{2}$ monopropellant within a micro-chemical reactor chamber, decorated with $\mathrm{RuO}_{2}$ nanorods (NRs). The second reaction involves the electrolysis of dilute aqueous solutions of $\mathrm{H}_{2} \mathrm{SO}_{4}$ performed with the cathode electrode coated with different densities and sizes of $\mathrm{RuO}_{2} \mathrm{NRs}$. In the catalyzed $\mathrm{H}_{2} \mathrm{O}_{2}$ decomposition, the reaction rate is observed to decrease with increasing catalyst surface density because of a failure of the liquid to wet on the catalyst surface. In the electrolysis experiment, however, the reaction rate increased in proportion to the surface density of $\mathrm{RuO}_{2} \mathrm{NRs}$. In this case, the electrical bias applied to drive the electrolysis reaction also causes an electrostatic force of attraction between the fluid and the NR coated surface, and thus assures effective wetting.
\end{abstract}

\section{Keywords}

Catalyst, Nanomaterial, Wetting

\section{Introduction}

A properly functioning catalyst acts to lower the activation energy required to transform chemical reactant species into chemical reaction products. An electrocatalyst promotes this transition with the accompanying transfer of electrical charge. A potentially attractive group of new electro-catalyst materials is found among the class of materials that are now classified as nanomaterials. The physical dimensions of these nanomaterial catalysts act to increase their chemical activity by at least the following two 
recognized phenomena:

1) The large surface area provided by the catalyst material increases the interfacial contact area with the reactant fluid.

2) An electrode coated with nanomaterials may contain abrupt geometric features which produces a high electric field region near the electrode/catalyst surface.

In this investigation, the same $\mathrm{RuO}_{2} \mathrm{NR}$ coating was used to enhance the reactivity of two different chemical reaction systems. In the first case, the walls of a micro-reactor were coated with a $\mathrm{RuO}_{2} \mathrm{NR}$ film, for the purpose of enhancing the decomposition of a high concentration (30\%) $\mathrm{H}_{2} \mathrm{O}_{2}$ monopropellant fuel for implementation in a micropropulsion system for small satellites [1] [2]. In the second reaction system, the $\mathrm{RuO}_{2}$ NR coating was applied to the surface of a conductive electrode that was used to electrolyze an aqueous solution of $\mathrm{H}_{2} \mathrm{SO}_{4}$ [3]. The experimental results in both cases were analyzed in light of the relative degree of wetting that occurs on the nanomaterial catalyst surface and was found to be a significant factor in the coating's ability to function as a catalyst [4]-[13].

\section{Experimental Methodology}

Thin films of $\mathrm{RuO}_{2}$ NRs were deposited on a variety of rectangular substrate pieces such as a $\mathrm{Si}$ wafer, $\mathrm{Al}$ evaporation coated $\mathrm{Si}$ wafer $(\mathrm{Al} / \mathrm{Si})$, and $\mathrm{Ti}$ metal sheet. The nanorods were deposited by a reactive sputtering process which is governed by a self-assembly mechanism that was discussed more fully in a previous publication [14]. The nanorods were found to be rectangular in shape and capped by a pyramid shaped termination, see Figure 1 [14]. The nanorods were grown approximately $1.3 \mu \mathrm{m}$ long and range in width from 10 to $100 \mathrm{~nm}$ wide in the lateral dimension depending on growth conditions. The density and size of the resulting nanorods were found to vary for the different substrate materials.

The $\mathrm{RuO}_{2}$ material is an electrical conductor and can be treated electrically as shorted to the starting substrate surface [15]. The increase in the resulting material's
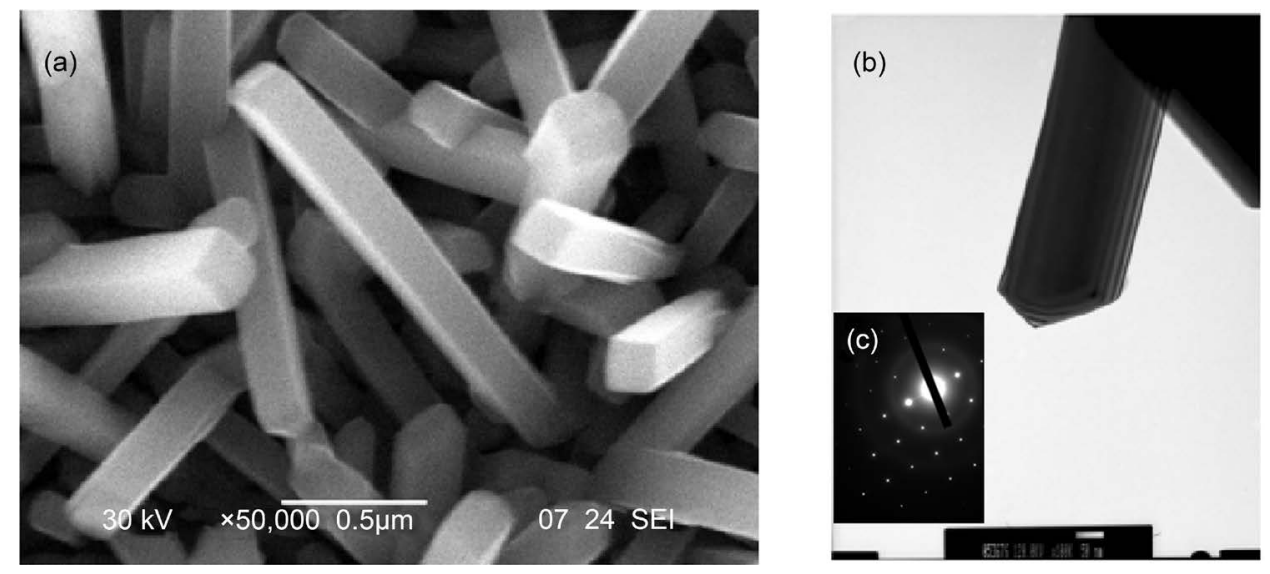

Figure 1. (a) SEM image of square $\mathrm{RuO}_{2}$ nanorods grown on a Si substrate. (b) TEM scan of an individual nanorod, showing an atomically sharp pyramid tip. (c) Diffraction pattern indicates crystallinity. 
interfacial surface area has been measured in previous experiments in our lab to be up to a factor of 10 greater than the original uncoated surface [3].

\section{Results and Discussion}

\subsection{Decomposition of $\mathrm{H}_{2} \mathrm{O}_{2}$ Monopropellant}

The image shown in Figure 2 is the catalyzed decomposition of a 30\% aqueous solution of $\mathrm{H}_{2} \mathrm{O}_{2}$ monopropellant flowing in a microchannel coated with $\mathrm{RuO}_{2} \mathrm{NRs}$. The chemical activity, observed as the production of bubbles along the vertical chamber walls, was visualized using a Vision Research Phantom High-Speed Camera operating at a frame rate of $6300 \mathrm{FPS}$. In this particular image greater activity is occurring on the right side of the chamber wall. The actual physical system finds the microchannel lying flat with the liquid $\mathrm{H}_{2} \mathrm{O}_{2}$ solution pumped from bottom to top in the image. The average rate of bubble formation along the low nanorod density side of the channel was 907 bubbles per second uniformly distributed along the channel wall, compared to 580 bubbles per seconds at widely-spaced formation sites on the high nanorod density side.

It was initially assumed that the greater decomposition activity would occur on the wall with the highest density of NRs, due to catalytic activity. Upon a review of SEM images of the channel walls, the opposite was true, there was greater relative activity on the side of the channel that was decorated with the lower density of $\mathrm{RuO}_{2} \mathrm{NRs}$. Heterogeneous reaction kinetics predicts that the higher density of reaction sites provided by the $\mathrm{RuO}_{2} \mathrm{NRs}$ should produce the greater chemical reactivity. Observation of a higher activity on the surface decorated with a lower density of $\mathrm{RuO}_{2}$ NRs suggests that something else is controlling the reaction rate, which is inversely dependent on nanorod density.

It is proposed that the reason for the lower chemical activity on the left side of the chamber image is a result from the inability of the $\mathrm{H}_{2} \mathrm{O}_{2}$ liquid to wet on the catalyst surface. The rate of chemical activity is observed as the production rate of bubbles along the catalyst wall. The production rate of bubbles is dramatically higher on the chamber wall that is decorated with the lower density of nanorods. A notable component of this observation is that the production rate of bubbles on the channel wall with
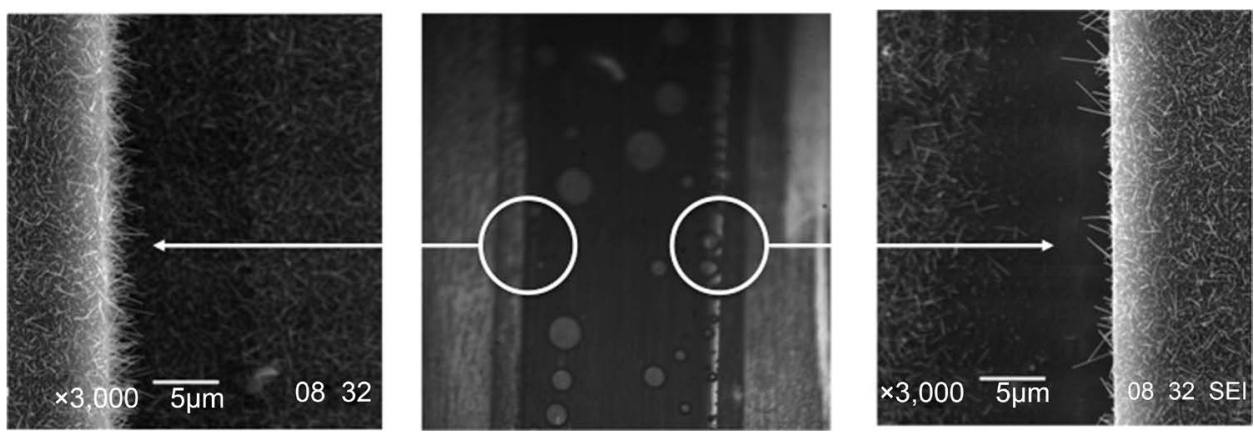

Figure 2. (Center) Top view photograph of bubble formation in the catalytic microchannel resulting from the decomposition of $\mathrm{H}_{2} \mathrm{O}_{2}$ monopropellant. The channel dimensions are $540 \mathrm{um}$ wide and 5 um deep. (Left and Right) Magnified views of nanorod films along the sidewalls. 
the higher nanorod density was actually limited to only a few sites on the channel wall. It is proposed that $\mathrm{H}_{2} \mathrm{O}_{2}$ decomposition is only occurring in regions on the channel wall where the density of NRs is low due to a defect, thus allowing wetting of the catalyst surface. The $\mathrm{H}_{2} \mathrm{O}_{2}$ liquid is repelled from the $\mathrm{RuO}_{2} \mathrm{NR}$ coated surface, similar to the way that a water droplet is repelled from a rose pedal or blade of grass (i.e., the Lotus Effect). Thus, the catalytic surface here displays a greater level of hydrophobicity; the degree of hydrophobicity may be quantified by measuring the contact angle of the droplet on the surface.

The phenomenon of wetting on surfaces covered with nanostructured materials has been the subject of considerable investigation for many years [4]-[13]. Suppose that the contact angle $\theta_{E}^{*}$ is defined as the angle formed by the droplet at the intersection of the three different phases; air, liquid and solid. A theoretical prediction for the contact angle $\left(\theta_{E}^{*}\right)$ obtained for nanomaterials similar to that used here can be found in the pioneering work by Casie and Baxter [16]. The contact angle is defined to be:

$$
\cos \theta_{E}^{*}=r_{\varphi} \varphi_{s} \cos \theta_{1}+\left(1-\varphi_{s}\right) \cos \theta_{2}
$$

where $r_{\varphi}=$ roughness of the wetted surface.

$\varphi_{s}=$ area fraction of the liquid-air interface.

$\theta_{1}=$ equilibrium contact angle on solid phase.

$\theta_{2}=$ equilibrium contact angle on air phase.

To further explore the nature of the unexpected chemical activity of the $\mathrm{H}_{2} \mathrm{O}_{2}$ solution droplet in contact with the $\mathrm{RuO}_{2} \mathrm{NR}$ catalyst coating, this wetting phenomenon was simulated with a droplet of liquid water, placed onto the $\mathrm{RuO}_{2} \mathrm{NR}$ surface. Our laboratory had in its possession a collection of $\mathrm{RuO}_{2} \mathrm{NR}$ samples which represented a range of different NR surface densities and sizes. The different samples were obtained by growing the NR samples for different lengths of time [14]. A collection of SEM images of different $\mathrm{RuO}_{2}$ NR samples is shown in Figure 3.

The application of a water droplet to the $\mathrm{RuO}_{2} \mathrm{NR}$ samples shown in Figure 3 is shown in Figure 4. The contact angle was measured as shown in Figure 5. $\mathrm{The}^{\mathrm{RuO}}$ NR coatings increase in both surface density of nanorods and size, principally girth of the NRs, with length of deposition time. The water droplet fails to wet on the $\mathrm{RuO}_{2} \mathrm{NR}$ coated surface as the NR surface density and NR girth increases (see Figure 6).

\subsection{Electrolysis of Dilute Aqueous Solutions of $\mathrm{H}_{2} \mathrm{SO}_{4}$}

In this portion of the investigation, conductive substrates $(\mathrm{Si}, \mathrm{Ti}$ and $\mathrm{Al} / \mathrm{Si})$ coated with thin films of $\mathrm{RuO}_{2} \mathrm{NRs}$ were used as electrodes in the electrolysis of aqueous solutions of $\mathrm{H}_{2} \mathrm{SO}_{4}$. Our laboratory has previously reported on the investigation of the use of NR coated electrodes for use as cathodes in the electrolysis of both basic and acidic aqueous solutions. A more complete description of these electrolysis experiments can be found in previously published work by Cross et al. [3] [17]. The nanomaterial coated electrode surface is similar to the $\mathrm{RuO}_{2}$ nanorods coated material whose SEM image was shown in Figure 1(a) [14]. The $\mathrm{RuO}_{2}$ material is an electrical conductor and can be treated 

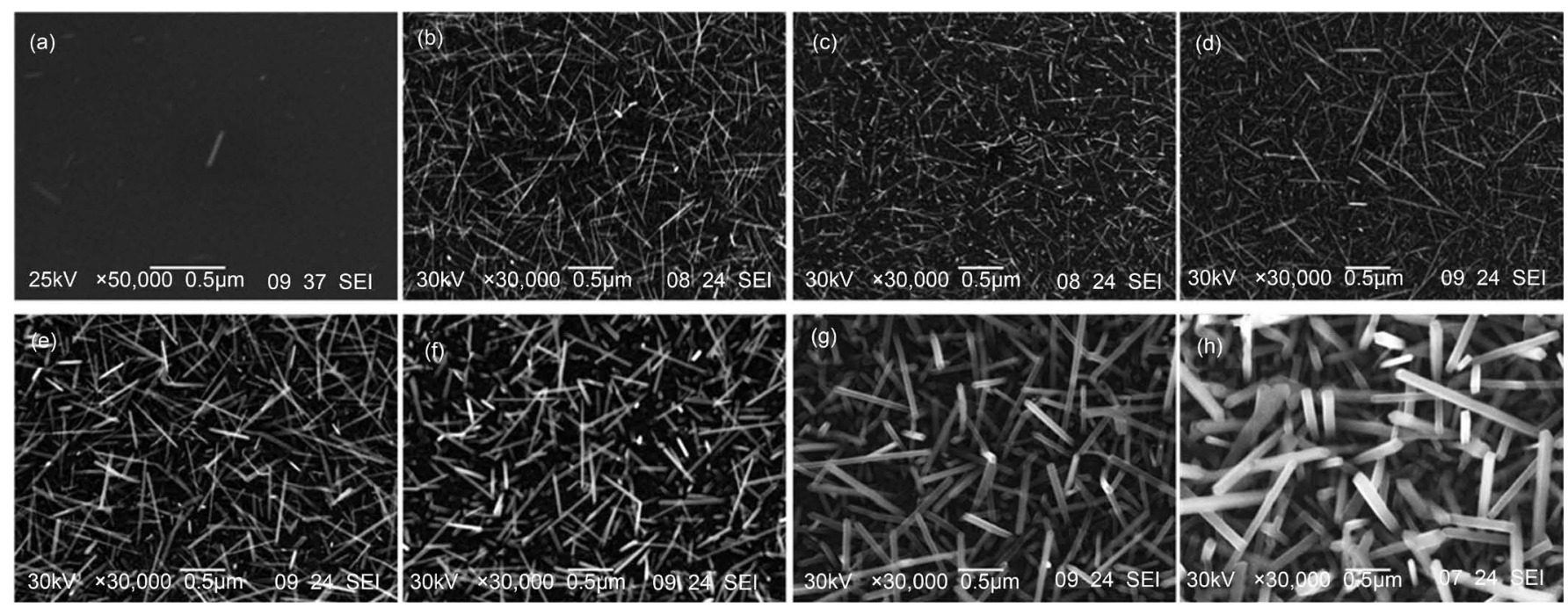

Figure 3. SEM images of $\mathrm{RuO}_{2}$ nanorods grown on aluminized $\mathrm{Si}$ substrate. The scale bar in all images is $0.5 \mu \mathrm{m}$. Nanorod length/width/density are: (a) $0.2 \mu \mathrm{m} / 18.6 \mathrm{~nm} / 0.2 \mu \mathrm{m}^{-2}$, (b) $0.7 \mu \mathrm{m} / 21.0 \mathrm{~nm} / 18.7 \mu \mathrm{m}^{-2}$, (c) $0.7 \mu \mathrm{m} / 19.0 \mathrm{~nm} / 19.3 \mu \mathrm{m}^{-2}$, (d) $0.8 \mu \mathrm{m} / 22.0$ $\mathrm{nm} / 16.6 \mu \mathrm{m}^{-2}$, (e) $1.0 \mu \mathrm{m} / 29.0 \mathrm{~nm} / 26.3 \mu \mathrm{m}^{-2}$, (f) $0.9 \mu \mathrm{m} / 34.0 \mathrm{~nm} / 28.0 \mu \mathrm{m}^{-2}$, (g) $1.3 \mu \mathrm{m} / 66.0 \mathrm{~nm} / 18.1 \mu \mathrm{m}^{-2}$, (h) $1.6 \mu \mathrm{m} / 100.0 \mathrm{~nm} / 16.4$ $\mu \mathrm{m}^{-2}$.

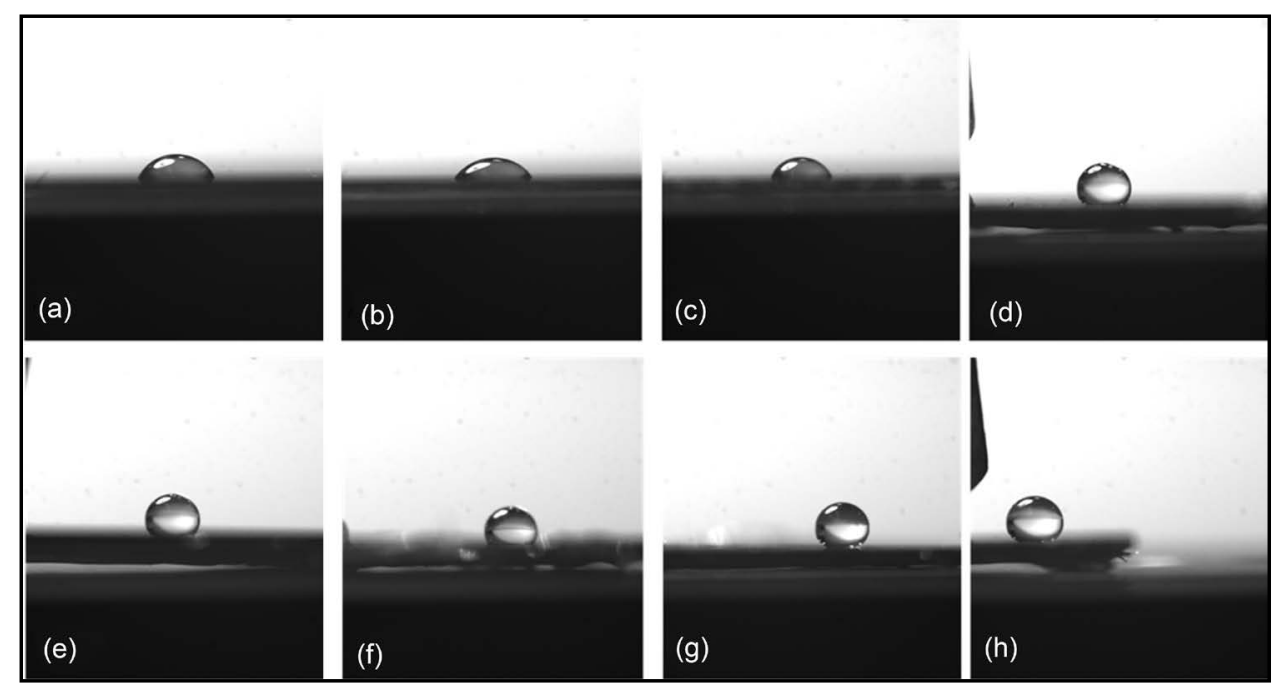

Figure 4. Photographs of DI water droplet on $\mathrm{RuO}_{2}$ nanorods. The total nanorod area (defined as the surface area of the nanorods times their density) are (a) $1.0 \mu \mathrm{m}^{2} / \mu \mathrm{m}^{2}$, (b) $2.1 \mu \mathrm{m}^{2} / \mu \mathrm{m}^{2}$, (c) 2.0 $\mu \mathrm{m}^{2} / \mu \mathrm{m}^{2}$, (d) $2.2 \mu \mathrm{m}^{2} / \mu \mathrm{m}^{2}$, (e) $4.1 \mu \mathrm{m}^{2} / \mu \mathrm{m}^{2}$, (f) $4.4 \mu \mathrm{m}^{2} / \mu \mathrm{m}^{2}$, (g) $7.2 \mu \mathrm{m}^{2} / \mu \mathrm{m}^{2}$, and (h) 11.5 $\mu \mathrm{m}^{2} / \mu \mathrm{m}^{2}$.

electrically as part of the electrode [15]. As stated above the increase in resulting interfacial area has been measured in previous experiments to be on the order of $10 \mathrm{X}$ greater [3].

The production rate of $\mathrm{H}_{2}$ per unit area of a flat cathode surface is directly proportional to the current density supplied to the cathode. An example of a Tafel plot [3] [17] obtained for an electrolysis cell with the NR decorated cathode electrode, with the voltage applied between the cathode electrode and the Saturated Calomel Electrode (SCE) 

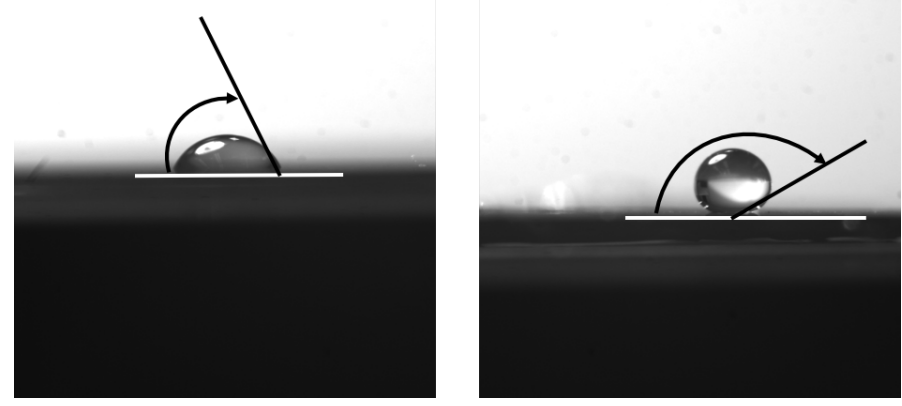

Figure 5. Definition of contact angle measurement for (left) a wetting sample and (right) a non-wetting sample.

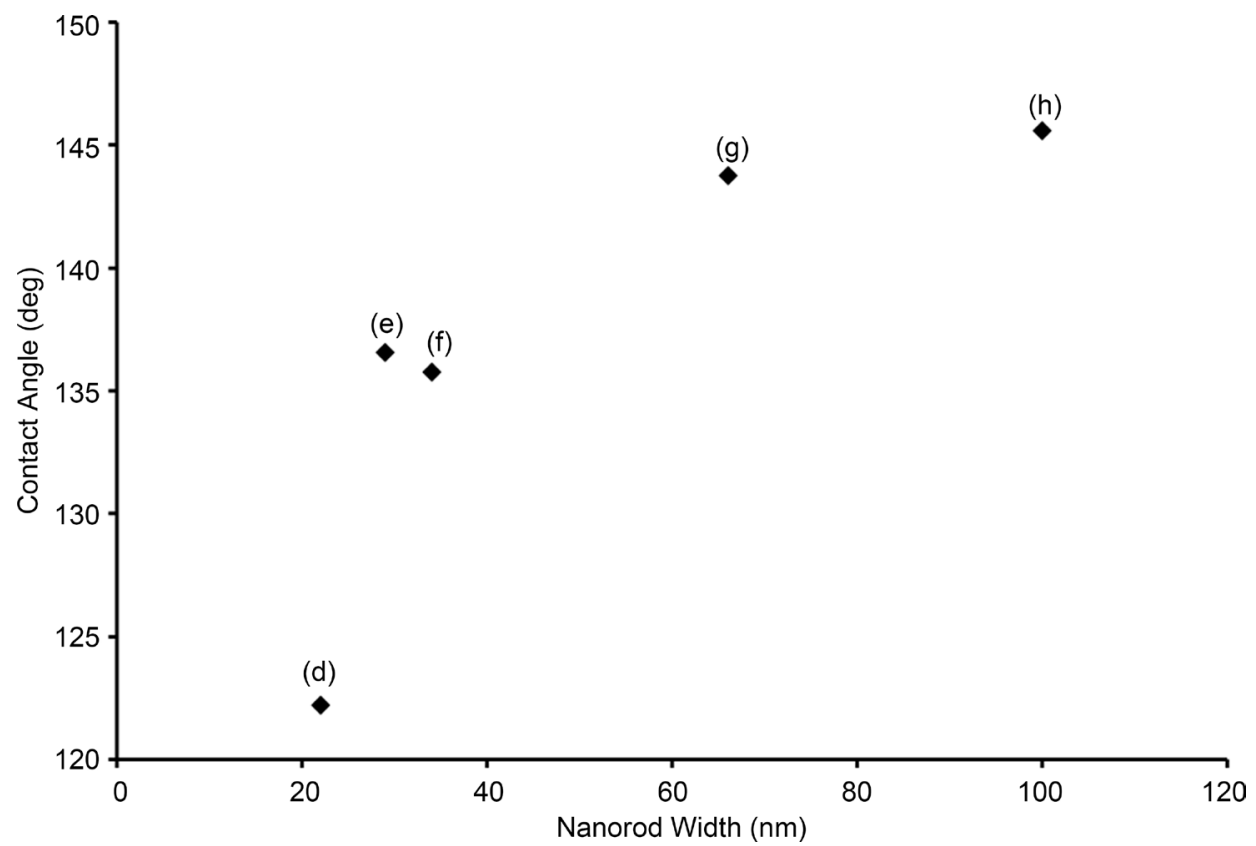

Figure 6. Contact angle of droplets on $\mathrm{RuO}_{2}$ nanorods. The data labels correspond to the images shown in Figure 3 and Figure 4.

reference, is shown in Figure 7. The anode in all cases was a piece of Pt wire and the cathode area was the macroscopic dimensions of the substrate piece. In this investigation the focus is on the overvoltage measured at the cathode electrode relative to the electrolyte. The cathode overvoltage $\left(\eta_{c}\right)$ is defined as the experimentally applied voltage, relative to the electrolyte, measured with the SCE reference electrode, minus the theoretical voltage. The theoretical value is obtained from the Gibbs' Free Energy for the reaction $\left(2 \mathrm{H}^{+}+2 \mathrm{e}^{-} \rightarrow \mathrm{H}_{2}(\mathrm{~g}), E_{\text {cell }^{0}}=0.0 \mathrm{~V}\right)$, plus a correction supplied by the Nernst Equation for the non-standard electrolyte concentration (in this case $V_{\text {Nernst }}=$ $0.0592 \log \left[\mathrm{H}^{+}\right],[18]$ and a correction for the voltage drop across the SCE reference electrode $\left(V_{\mathrm{CRE}}=0.2415 \mathrm{~V}\right)[19]$.

$$
\eta_{c}(V)=V_{\text {cathode }}-\left(E_{\text {cell }^{0}}+V_{\text {Nernst }}+V_{\text {SCE }}\right)
$$




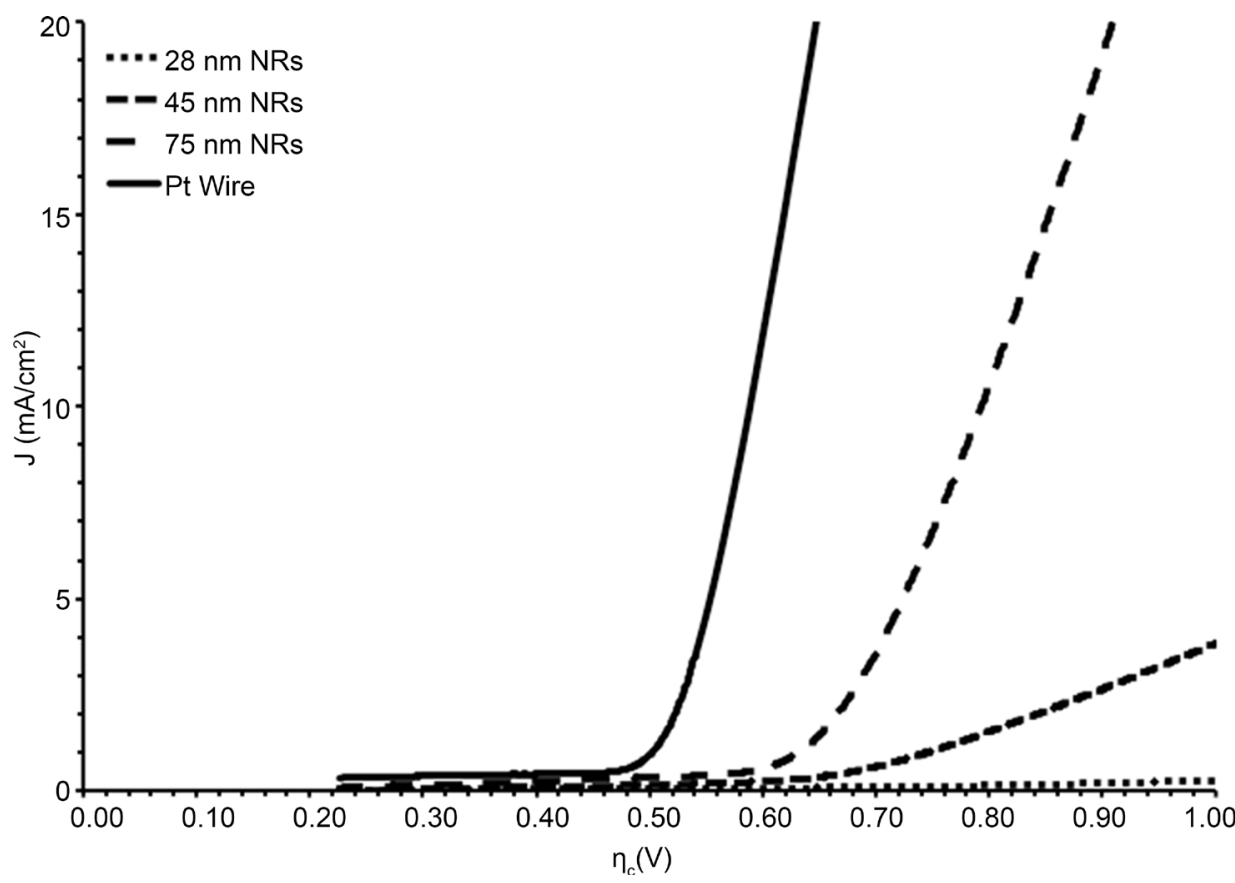

Figure 7. Cathode overvoltage of various electrodes including those coated with $\mathrm{RuO}_{2}$ nanorods of varying width. A 3.5\% aqueous solution of $\mathrm{H}_{2} \mathrm{SO}_{4}$ was used as the electrolyte and a Pt wire use used as the anode.

The voltage required to induce current flow was lowest for the case of the cathode constructed of Pt and otherwise was found to vary with the material used to make the electrode.

The actual interfacial area of the cathode electrode surface should take into consideration the contribution of the nanorod coating. The total surface area for a nanorod coated electrode is calculated from the number density of nanorods per unit surface area times the surface area of an individual nanorod, with dimensions measured from an SEM image. A corrected current density was obtained from the measured current densities shown in Figure 7 and the corrected interfacial surface areas calculated from dimensions measured in Figure 3. Once corrected for surface area, the current density measured for the three nanorod coated samples merged into one, see Figure 8. This result suggests that the reason for the increase in the performance of the denser nanorod coated electrode is explained as the increased interfacial contact area. This observed increase in activity would not have been observed if surface wetting was limiting the electrochemical reaction at the higher nanorod densities.

The shape of an individual nanorod is rectangular with sharp edges and termination in a pyramid shape peak, as was shown in Figure 1(b). When electrically biased in free space, a high electric field region is formed around the exterior of the rectangular nanorod. In a water solution the surrounding medium is as a fluid with a finite relative permittivity that reduces the strength of this field. An interesting case exists in a liquid water bath during electrolysis, where the generation of bubbles presents the opportunity of an enhanced field strength in the vicinity of the nanorod electrode. 


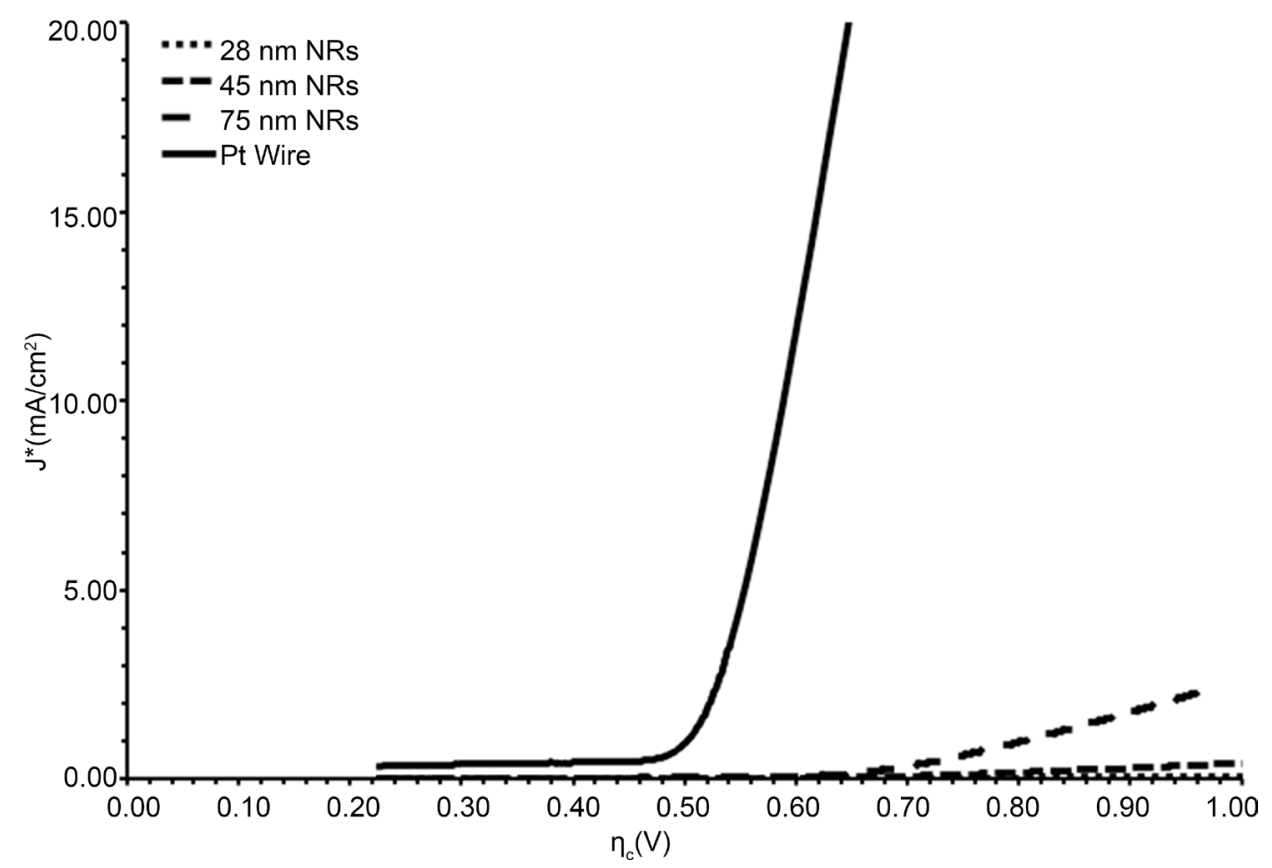

Figure 8. Cathode overvoltage of various electrodes including those coated with $\mathrm{RuO}_{2}$ nanorods of varying width. A $3.5 \%$ aqueous solution of $\mathrm{H}_{2} \mathrm{SO}_{4}$ was used as the electrolyte and a $\mathrm{Pt}$ wire use used as the anode.

The electrolysis process involves the transfer of electrical charge from one chemical species to another [20] [21]. The electron in the vicinity of the reacting molecule can be modeled as a particle in a one dimensional potential well. When the potential well is placed in an electrical field, the energy required to escape the potential well is reduced to $E_{a}-\Delta E$ (see Figure 9). A nanorod coating on a biased electrode surface is similar to this simple model and can be used to reduce the energy required for electrolysis.

The wettability of the $\mathrm{RuO}_{2} \mathrm{NR}$ coated electrode material can be measured directly by observing the contact angle of a water droplet on the surface of the electrode material. The contact angle is inversely proportional to the degree of wetting that the water medium droplet makes with the nanorod coated surface. The contact angle should increase with the density of nanorods and/or the total interfacial area of the nanorod surface as predicted by the Casey-Baxter law for nanomaterial coated surfaces. The rate of the electrolysis reaction should be reduced by the reduction in wetting on the nanorod coated surface. This however is not what was observed, and the production rate of hydrogen increased with the surface density of $\mathrm{RuO}_{2}$ nanorods, see Figure 10. One explanation for this observed behavior is that the electrical bias applied between the fluid droplet and nanorod surface influences the physical interaction of the two materials toward one another. It is proposed that the electrically biased surface electrostatically attracts the fluid to the nanorod coated electrode surface.

This was also observed independently in Figure 11 and Figure 12, where a droplet of biased and unbiased DI water and aqueous $\mathrm{H}_{2} \mathrm{SO}_{4}$ solution where placed side-by-side on a $\mathrm{RuO}_{2} \mathrm{NR}$ coated substrate surface for comparison. There is no obvious difference 
(a)

$E_{a}$

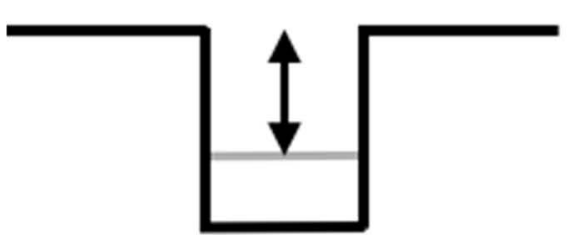

(b)

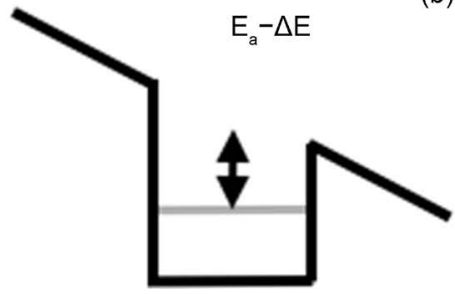

Figure 9. The simplified model of a particle in a finite, $1-\mathrm{D}$ quantum well: (a) $\mathrm{V}=0$ and (b) $\mathrm{V}=$ finite magnitude.

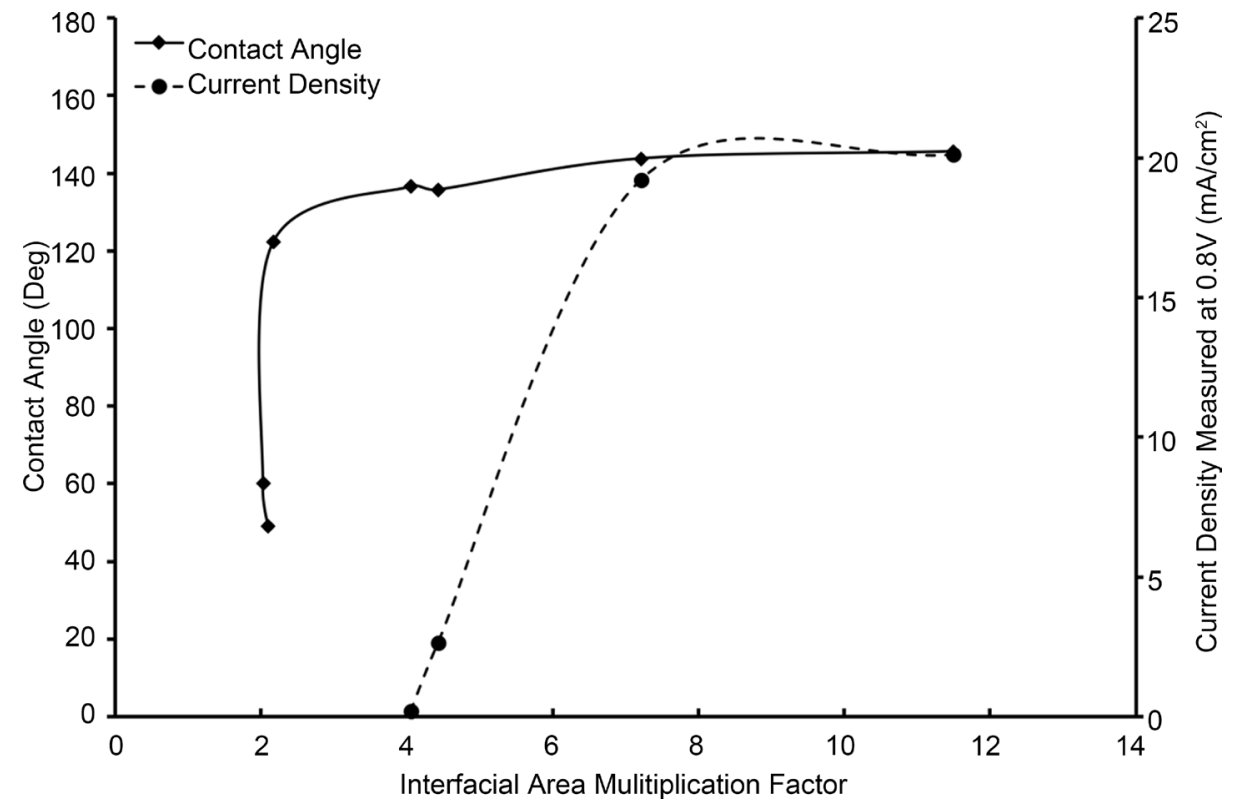

Figure 10. Contact angle and current density of $\mathrm{RuO}_{2}$ nanorods grown on aluminized Si substrate. The electrolysis cell used a 3.5\% aqueous solution of $\mathrm{H}_{2} \mathrm{SO}_{4}$ as the electrolyte and a $\mathrm{Pt}$ wire use used as the anode. The interfacial area multiplication factor is defined as the surface area of the nanorods times their density.

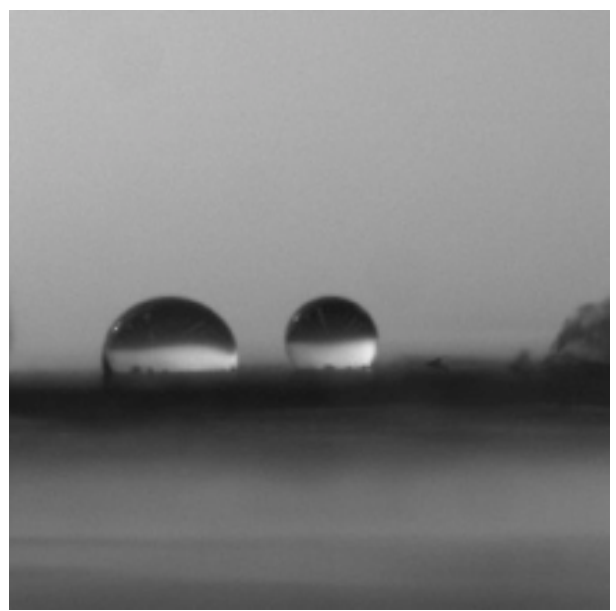

Figure 11. Photographs of water droplets on $\mathrm{RuO}_{2}$ nanorods. The drop on the left is a dilute solution of $\mathrm{H}_{2} \mathrm{SO}_{4}$, while the drop on the right is DI water. 

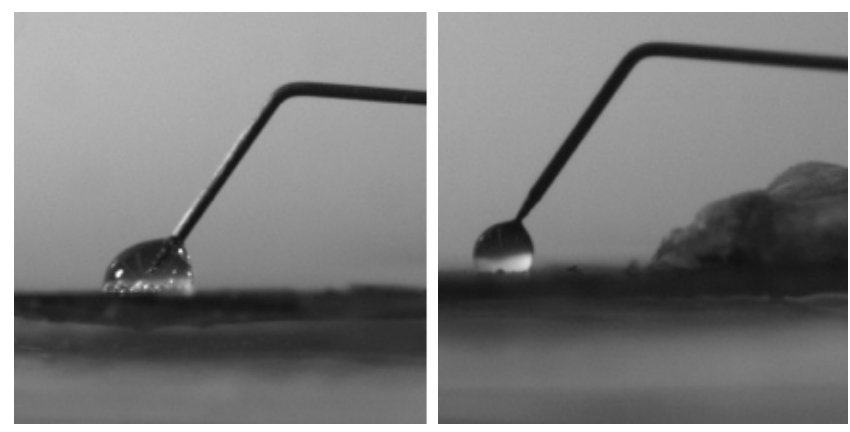

Figure 12. Photographs of electrically charged water droplets on $\mathrm{RuO}_{2}$ nanorods. (Left) The drop is a dilute solution of $\mathrm{H}_{2} \mathrm{SO}_{4}$; (Right) The drop is DI water.

between the wetting behavior of these two unbiased droplets, see Figure 11. In Figure 12 , the same two droplets are biased positively relative to the nanorod surface. In the case of the dilute $\mathrm{H}_{2} \mathrm{SO}_{4}$ solution droplet (left), the droplet body is attracted to the nanorod coated surface and the contact angle is decreased indicating an increased level of wetting. It is also observed that the electrical bias has also initiated electrolysis at the nanorod coated surface. For the case of the biased DI water droplet (right), no noticeable change can be observed in the contact angle. This is to be expected as the conductivity of DI water is on the order of $10^{6} \Omega-\mathrm{cm}$, and no charge can be transferred to the droplet from the charging electrical probe.

\section{Conclusions}

In the case of the catalyzed decomposition of $\mathrm{H}_{2} \mathrm{O}_{2}$ in a micro-chemical reactor chamber decorated with $\mathrm{RuO}_{2} \mathrm{NRs}$, the decomposition rate decreases with catalyst surface concentration because of a failure of the liquid to wet on the catalyst surface. The inability of liquid fluids to wet on aligned nanostructured material solids has been predicted by the Cassie-Baxter effect. The critical angle of a water droplet when placed on a surface decorated with different densities of nanorods was measured. The reduction in the decomposition rate of the $\mathrm{H}_{2} \mathrm{O}_{2}$ is a result of decreased wetting of the $\mathrm{H}_{2} \mathrm{O}_{2}$ liquid on the $\mathrm{RuO}_{2} \mathrm{NR}$ coated surfaces.

In the case of the electrolysis experiment with a liquid aqueous solution, the reaction rate increased in proportion to the surface density of $\mathrm{RuO}_{2}$ NRs. The reason why wetting was not a factor in controlling the reaction rate in this case was the presence of an electrostatic force developed between the solution and the nanorod decorated surface. In the case of electrolysis, the applied electrostatic potential difference produces an electrostatic force of attraction between the fluid droplet and the nanorod decorated electrode. In this case the surface wetting is enhanced by the applied electrostatic force of attraction between the fluid and the catalyst surface. The force of attraction insures effective wetting of the catalyst surface.

\section{Acknowledgements}

This work was supported by NASA under Cooperative Agreement NNX09AO60A. 


\section{References}

[1] Widdis, S.J., Asante, K, Hitt, D.L., Cross, M.W., Varhue, W.J. and McDevitt, M.R. (2013) A MEMS-Based Catalytic Microreactor for a $\mathrm{H}_{2} \mathrm{O}_{2}$ Monopropellant Micropropulsion System. IEEE/ASME Transactions on Mechatronics, 18, 1250-1258. https:/doi.org/10.1109/TMECH.2013.2249085

[2] Hitt, D.L., Zakrzwski, C.M. and Thomas, M.K. (2001) MEMS-Based Satellite Micropropulsion via Catalyzed Hydrogen Peroxide Decomposition. Smart Materials and Structures, 10, 1163-1175. https:/doi.org/10.1088/0964-1726/10/6/305

[3] Cross, M.W., Stewart, M., Pelletier, K.P. and Varhue, W.J. (2012) $\mathrm{RuO}_{2}$ Nanorod Coated Cathode for the Electrolysis of Water. International Journal of Hydrogen Energy, 37, 21662172. https:/doi.org/10.1016/j.ijhydene.2011.10.075

[4] Mittal K.L. (2015) Advances in Contact Angles, Wettability and Adhesion. John Wiley + Sons, Hoboken.

[5] Jianguo, L.V., Zhu, J., Huang, K., Meng, F., Song, X. and Sun, Z. (2011) Tunable Surface Wettability of ZnO Nanorods Prepared by Two Step Methods. Applied Surface Science, 257, 7534-7538. https:/doi.org/10.1016/j.apsusc.2011.03.113

[6] Marmur, A. (2003) Wetting on Hydrophobic Rough Surfaces: To Be Heterogeneous or Not To Be? Langmuir, 19, 8343-8348. https:/doi.org/10.1021/la0344682

[7] Cao, Z., Stevens, M.J., Carrillo, J-M. Y. and Dobrynin, V. (2015) Adhesion and Wetting of Soft Nanoparticles on Textured Surfaces: Transistion between Wenzel and Cassie-Baxter States. Langmuir, 31, 1693-1703. https:/doi.org/10.1021/la5045442

[8] Johnson, R.E. and Dettre, R.H. (1964) Contact Angle Hysteresis. In: Fowkes, F.M., Ed., Contact Angle, Wettablity and Adhesion, ACS Advances in Chemistry Series, 43, American Chemical Society, Washington DC, 112-135. https:/doi.org/10.1021/ba-1964-0043.ch007

[9] Choi, W., Tuteja, A., Mabry, J.M., Cohen, R.E. and McKinley G.H. (2009) A Modified Cassie-Baxter Relationship to Explain Contact Angle Hysteresis and Anisotropy on NonWetting Textured Surfaces. Journal of Colloid and Interface Science, 339, 208-216. https:/doi.org/10.1016/j.jcis.2009.07.027

[10] Hang, T., Hu, A., Ling, H., Li, M. and Mao, D. (2010) Super-Hydrophobic Nickel Films with Micro-Nano Hierarchical Structure Prepared by Electrodeposition. Applied Surface Science, 256, 2400-2404. https:/doi.org/10.1016/j.apsusc.2009.10.074

[11] Raza, M.A., Zandvliet, J.W., Poelsema, B. and Kooij, E.S. (2015) Hydrophobic Surfaces with Tunable Dynamic Wetting Properties via Colloidal Assembly of Silica Microspheres and Gold Nanoparticles. Journal of Sol-Gel Science and Technology, 74, 357-367. https:/doi.org/10.1007/s10971-014-3476-4

[12] Torrisi, L. and Scolaro, C. (2015) Treatment Techniques on Aluminum to Modify the Surface Wetting Properties. Acta Physica Polonica A, 128, 48-53.

https:/doi.org/10.12693/APhysPolA.128.48

[13] Haapanen, J., Aromma, M., Teisala, H., Tuominen, M., Stepien, M., Saarinen, J.J., Heikkila, M., Toivakka, M., Kuusipalo, J. and Makela, J.M. (2015) Binary $\mathrm{TiO}_{2} / \mathrm{SiO}_{2}$ Nanoparticle Coating for Controlling the Wetting Properties of Paperboard. Materials Chemistry and Physics, 149-150, 230-237. https:/doi.org/10.1016/j.matchemphys.2014.10.011

[14] Cross, M.W., Varhue, W.J., Hitt, D.L. and Adams, E. (2008) Control of Ruthenium Oxide Nanorod Length in Reactive Sputtering. IOP Publishing Ltd., Bristol 19. https:/doi.org/10.1088/0957-4484/19/04/045611

[15] Cross, M.W. and Varhue, W.J. (2012) Influence of Electrostatic Forces on the Growth of One-Dimensional Nanostructures. Journal of Nanomaterials, 2012, Article ID: 105782. 
https:/doi.org/10.1155/2012/105782

[16] Casssie, A.B.D. and Baxter, S. (1944) Wettability of Porous Surfaces. Transactions of the Faraday Society, 40, 546-551. https:/doi.org/10.1039/tf9444000546

[17] Cross, M.W., Varhue, W.J. and Valdez, T. (2012) Pt Doped $\mathrm{RuO}_{2}$ Nanorod Coated Cathode for the Electrolysis of Water. International Journal of Hydrogen Energy, 37, 13243.

https:/doi.org/10.1016/j.ijhydene.2011.10.075

[18] Silberberg, M.S. (2006) Chemistry, the Molecular Nature of Matter and Charge. 4th Edition, McGraw Hill, New York.

[19] Wendt, H. and Plzak, V. (1983) Electrocatalytic and Thermal Activation of Anodic Oxygenand Cathodic Hydrogen-Evolution in Alkaline Water Electrolysis. Electrochim Acta, 28, 27-34. https:/doi.org/10.1016/0013-4686(83)85083-X

[20] Tro, N. (2006) Chemistry: A Molecular Approach. 1st Edition, Prentice Hall, Upper Saddle River.

[21] Djafour, A., Matoug, M., Bouras, H., Bouchekima, B., Aida, M.S. and Azoui, B. (2011) Photovoltaic-Assited Alkaline Water Electrolysis: Basic Principals. International Journal of Hydrogen Energy, 36, 4117-4124. https:/doi.org/10.1016/j.ijhydene.2010.09.099

\section{Submit or recommend next manuscript to SCIRP and we will provide best service for you:}

Accepting pre-submission inquiries through Email, Facebook, LinkedIn, Twitter, etc.

A wide selection of journals (inclusive of 9 subjects, more than 200 journals)

Providing 24-hour high-quality service

User-friendly online submission system

Fair and swift peer-review system

Efficient typesetting and proofreading procedure

Display of the result of downloads and visits, as well as the number of cited articles

Maximum dissemination of your research work

Submit your manuscript at: http://papersubmission.scirp.org/

Or contact aces@scirp.org 